\title{
Antagonistics against pathogenic Bacillus cereus in milk fermentation by Lactobacillus plantarum ZDY2013 and its anti-adhesion effect on Caco-2 cells against pathogens
}

\author{
Zhihong Zhang, ${ }^{*}$ Xueying Tao, ${ }^{*}$ Nagendra P. Shah, $†$ and Hua Wei ${ }^{* 1}$ \\ *State Key Laboratory of Food Science and Technology, Nanchang University, Nanchang 330047, China \\ †Food and Nutritional Science, School of Biological Science, The University of Hong Kong, Pokfulam Road, Hong Kong 999077, China
}

\begin{abstract}
Lactobacillus plantarum ZDY2013 is a potential probiotic isolated from fermented bean acid. In this study, we aimed to evaluate the in vitro antimicrobial activity of this organism against Bacillus cereus in milk fermentation, the antiadhesion ability on intestinal epithelial cells, as well as its ability to abrogate the cytotoxic effect and expression levels of genes. We found no antimicrobial activity produced by $L$. plantarum once the $\mathrm{pH}$ was adjusted to 6.0 and 7.0. The $\mathrm{pH}$ decreased continuously when $L$. plantarum and $B$. cereus were co-incubated during milk fermentation, which caused a decrease in the $B$. cereus counts. Antiadhesion assays showed that $L$. plantarum can significantly inhibit the adhesion of enterotoxin-producing B. cereus ATCC14579 and pathogenic B. cereus HN001 by inhibition, competition, and displacement. The supernatants of $B$. cereus, either alone or in conjunction with L. plantarum, caused damage to the membrane integrity of Caco- 2 cells to release lactate dehydrogenase. In addition, L. plantarum tended to attenuate proinflammatory cytokine and oxidative stress gene expression on Caco-2 cells, inducing with $B$. cereus HN001 supernatants. This study provided systematic insights into the antagonistic effect of $L$. plantarum ZDY2013, and the information may be helpful to explore potential control measures for preventing food poisoning by lactic acid bacteria.
\end{abstract}

Key words: Lactobacillus plantarum ZDY2013, Bacillus cereus, milk fermentation, antiadhesion, cytotoxic effect

\section{INTRODUCTION}

Probiotic bacteria are incorporated into foods and beverages and sold as nutritional supplements for improving human health. They are predominantly repre-

Received November 2, 2015.

Accepted December 3, 2015.

${ }^{1}$ Corresponding author: weihua@ncu.edu.cn sented by the genera Lactobacillus and Bifidobacterium (Marco and Tachon, 2013; García-Ruiz et al., 2014). The beneficial effects are mainly related to the maintenance of a healthy gut microbiota of the host, reduction in serum cholesterol levels, regulation of immune homeostasis, and prevention of diarrhea (Chouraqui et al., 2004; Leahy et al., 2005; Derrien and van Hylckama Vlieg, 2015).

Some lactic acid bacteria have been used widely as probiotics in dairy products, but it is still necessary to isolate more functional probiotic bacteria. To be a potential candidate of probiotics, the microorganism should resist extreme acid and bile salt in the gastrointestinal tract (Derrien and van Hylckama Vlieg, 2015), adhere to the intestinal mucosa (as adhesion is an important characteristic of their beneficial function; Collado et al., 2006, 2007), and produce antimicrobial substances in vitro and in vivo.

Recently, Lactobacillus plantarum has been isolated from many fermented foods. Generally, most are evaluated for their tolerance to extreme acid and bile salt environment, antioxidant activity ( $\mathrm{Li}$ et al., 2012; Kuda et al., 2015), antibacterial activity (da Silva Sabo et al., 2014), lactic acid production (Zhang and Vadlani, 2015), cell envelope damage (Bravo-Ferrada et al., 2015), and for stimulating the immunomodulation (Zago et al., 2011; Górska et al., 2014). In our previous work, we isolated L. plantarum ZDY2013 from traditional acid bean fermented under natural conditions (Huang et al., 2015). This strain was able to tolerate an extreme $\mathrm{pH}$ of 2.0 for more than $6 \mathrm{~h}$ and remain alive under $0.45 \%$ bile salt for $3 \mathrm{~h}$. In addition, oral administration of $L$. plantarum ZDY2013 could alter the composition of the microbiota in the intestine of mice and enhance the populations of Lactobacillus and Bifidobacterium group in either colon or cecum. However, the antagonistic activity of $L$. plantarum in fermented food or cell lines has not been assessed.

Bacillus cereus is a well-known food-borne pathogen that is ubiquitously distributed in nature and easily contaminates many kinds of foods, especially those of 
plant origin, as well as milk and dairy products (Hwang and Park, 2015; Zhang et al., 2016). The presence of $B$. cereus in processed dairy foods is responsible for a variety of food-borne infections and intoxications for its enterotoxin or vomitoxin production (Røssland et al., 2005). In the current study, we systematically studied the antagonistic effect of $L$. plantarum ZDY2013 on enterotoxin-producing $B$. cereus ATCC14579 and pathogenic B. cereus HN001 in vitro and during milk fermentation, as well as the antiadhesion of $\mathrm{B}$. cereus on Caco-2 intestinal epithelial cells to determine whether the $B$. cereus can be inhibited by $L$. plantarum ZDY2013. Additionally, the ability of L. plantarum to abrogate the cytotoxic effect, and the mRNA expression levels in intestinal cells triggered by cell-free supernatants of $B$. cereus was also included.

\section{MATERIALS AND METHODS}

\section{Bacterial Strains and Growth Condition}

Acid-resistant L. plantarum ZDY2013 was isolated from fermented bean acid and cultured anaerobically in de Man, Rogosa, Sharpe broth (MRS; Beijing Solarbio Science and Technology Co. Ltd., Beijing, China) at $37^{\circ} \mathrm{C}$ for $24 \mathrm{~h}$. Bacillus cereus ATCC14579, obtained from the American Type Culture Collection (http:// www.atcc.org/en.aspx), is an enterotoxin-positive (hemolysin BL, nonhemolytic enterotoxin and cytotoxin K) type strain (Ngamwongsatit et al., 2008). Bacillus cereus HN001 was isolated from vomitus of a patient involved in a food poisoning incidence in Henan province (China) and stored in Academy of Military Medical Science (Beijing, China). All the B. cereus strains were cultured in Luria-Bertani (LB) medium at $37^{\circ} \mathrm{C}$.

\section{Inhibiting the Growth of B. cereus by L. plantarum}

Type strain B. cereus ATCC14579 and pathogenic $B$. cereus HN001 were used for measuring antibacterial activities of L. plantarum. Lactobacillus plantarum was activated in MRS for $24 \mathrm{~h}$ at $37^{\circ} \mathrm{C}$. Each B. cereus was grown in $\mathrm{LB}$ for $12 \mathrm{~h}$ at $37^{\circ} \mathrm{C}$ in triplicate, and the final concentrations of each bacterium were adjusted to $10^{6}$ $\mathrm{cfu} / \mathrm{mL}$.

The antibacterial activity was performed according to the previous study with some modifications (Huang et al., 2015). Briefly, aliquots of $200 \mu \mathrm{L}$ of $B$. cereus suspension were spread on LB agar plates to give confluent colonies, dried at room temperature, and holes in the agar were made with oxford cup (stainless steel cylinder; diameter $=7.8 \pm 0.1 \mathrm{~mm}$ ) and aliquots of $200 \mu \mathrm{L}$ of $L$. plantarum suspension were dropped into the holes. The antibacterial activity of $L$. plantarum suspension adjusted to $\mathrm{pH} 6.0$ and 7.0 was also tested. Agar plates were incubated in an aerobic at $37^{\circ} \mathrm{C}$ for $10 \mathrm{~h}$ and then the diameter of the inhibition zone around each cup was measured. All experiments were performed in triplicate.

\section{Preparation of Milk Samples}

Milk powder (Wondersun Inc., Heilongjiang, China) was purchased from the local supermarket. The empty flasks were autoclaved at $121^{\circ} \mathrm{C}$ for $21 \mathrm{~min}$ and $30 \mathrm{~mL}$ of $10 \%$ (wt/vol) reconstituted sterile milk was added. The sterile milk was inoculated with B. cereus (ATCC14579/ HN001) at about $10^{2}$ to $10^{3} \mathrm{cfu} / \mathrm{mL}$ and L. plantarum at about $10^{4}$ to $10^{5} \mathrm{cfu} / \mathrm{mL}$. Control groups were inoculated with B. cereus ATCC14579 or B. cereus HN001 alone. Samples were incubated anaerobically at $37^{\circ} \mathrm{C}$, and samples for $\mathrm{pH}$ measurement and analyses were withdrawn at different fermentation time points $(0,24$, 36 , and $48 \mathrm{~h}$ ). All experiments were repeated twice.

\section{L. plantarum Adhesion Assay}

Caco-2 cells were obtained from the American Type Culture Collection and grown in Dulbecco's modified Eagle's medium (DMEM; Solarbio, Beijing, China) supplemented with $10 \%$ fetal calf serum and antibiotics (100 U/mL of penicillin, $100 \mu \mathrm{g} / \mathrm{mL}$ of streptomycin) at $37^{\circ} \mathrm{C}$ in an atmosphere of $5 \% \mathrm{CO}_{2}$ and $95 \%$ air at constant humidity. The adherence of $L$. plantarum to Caco-2 cells was carried out as described by Leite et al. (2015), with some modifications. A monolayer of cells was seeded at a concentration of $2.5 \times 10^{5}$ cells per well in 6-well tissue plates and incubated in an atmosphere of $5 \% \mathrm{CO}_{2}$ and $95 \%$ air at $37^{\circ} \mathrm{C}$ for $18 \mathrm{~h}$. The monolayer was washed twice with $1.5 \mathrm{~mL}$ of PBS $(\mathrm{pH}$ 7.4) to remove antibiotics from the cells, then added with approximately $10^{8}$ cfu of $L$. plantarum, which was suspended by $2 \mathrm{~mL}$ of DMEM medium without antibiotics. Subsequently, the cells were incubated for $2 \mathrm{~h}$ and gently washed 3 times with PBS to remove nonadhered $L$. plantarum. Caco- 2 cells and adhered bacteria were disrupted using trypsin-EDTA solution (Solarbio) and the L. plantarum counts were performed in the MRS agar medium. Adhesion was expressed as the percentage of $L$. plantarum adhered with respect to total number of L. plantarum added initially.

\section{Competition Between L. plantarum and B. cereus for Cell Adhesion}

Competitiveness was assessed by adding $10^{8} \mathrm{cfu} /$ $\mathrm{mL}$ of L. plantarum and $10^{8} \mathrm{cfu} / \mathrm{mL}$ of $B$. cereus (ATCC14579/HN001) simultaneously to Caco-2 mono- 
layer cells in 6-well tissue plates; L. plantarum and $B$. cereus were suspended by DMEM medium without antibiotics or serum. After $2 \mathrm{~h}$ of incubation, nonbound probiotics and pathogens were washed and adhered bacteria were detached by trypsin-EDTA solution. The counts of the adhered bacteria were enumerated in the appropriate agar media. Competitive exclusion was calculated as the percentage of adhesion of $B$. cereus added in combination with $L$. plantarum relative to $B$. cereus bound in the absence of $L$. plantarum (control).

\section{Inhibition of B. cereus Adhesion}

To test the ability of the $L$. plantarum to inhibit the adhesion of B. cereus ATCC14579 and B. cereus HN001, L. plantarum $\left(10^{8} \mathrm{cfu}\right.$, suspended by $2 \mathrm{~mL}$ of DMEM medium without antibiotics or serum) was first added to the monolayer of Caco-2 cells and incubated for $1 \mathrm{~h}$. The supernatants were removed and B. cereus (ATCC14579/HN001, suspended by $2 \mathrm{~mL}$ of DMEM medium without antibiotics or serum) were added to the wells and incubated for $1 \mathrm{~h}$. Adhered bacteria ( $L$. plantarum and B. cereus) were detached from Caco-2 cells and the bacterial counts were performed. The adhesion inhibition was expressed as the percentage of the $B$. cereus in the presence and absence of L. plantarum.

\section{Displacement of Adhered B. cereus}

The ability of the $L$. plantarum to displace already adhered $B$. cereus was assessed according to GarcíaRuiz et al. (2014). Bacillus cereus ATCC14579 or B. cereus HN001 were first added to Caco-2 cells. After $1 \mathrm{~h}$ of incubation, the supernatants were removed and L. plantarum (suspended by $2 \mathrm{~mL}$ of DMEM alone) were added to the cells and the tissue plates incubated for $1 \mathrm{~h}$; then, the counts of adhered bacterial were carried out. Displacement of B. cereus was calculated as described above.

\section{Lactate Dehydrogenase Activity in Caco-2 Cells}

Cell-free supernatants prepared from 12-h cultures of $B$. cereus were centrifuged at $9,000 \times g$ for 5 min at $4^{\circ} \mathrm{C}$ followed by filtration of the supernatants through a $0.22-\mu \mathrm{m}$ pore size filter to remove any remaining bacteria. Differentiated Caco-2 cells grown in 6-well tissue plates were co-incubated with $0.4 \mathrm{~mL}, 2$-fold serial dilutions (1:5 to $1: 80$ ) of $B$. cereus (ATCC14579/HN001) cell-free supernatants in the absence and presence of $10^{8} \mathrm{cfu}$ of L. plantarum at $37^{\circ} \mathrm{C}$ in an atmosphere $5 \%$ $\mathrm{CO}_{2}$ and $95 \%$ air for $2 \mathrm{~h}$. To each well $2 \mathrm{~mL}$ of DMEM medium without antibiotics or serum was added, and the extracellular lactate dehydrogenase (LDH) activ- ity was measured using the LDH assay kit (Njjcbio, Nanjing, China), following the manufacturer's specifications. Aliquots of $20 \mu \mathrm{L}$ of Caco-2 supernatants were added with the enzyme substrate and incubated at $37^{\circ} \mathrm{C}$ for $15 \mathrm{~min}$. The absorbance value was measured at $450 \mathrm{~nm}$.

\section{RNA Isolation and Gene Expression Analysis by Real-Time PCR}

Caco-2 monolayer cells were treated with $1 \mathrm{~mL}$ of cell-free supernatants of $B$. cereus HN001 (stationary stage) in 6 -well tissue plates, and $1 \mathrm{~mL}$ of antibioticand serum-free DMEM was added. Cells treated with 1 $\mathrm{mL}$ of LB medium and $1 \mathrm{~mL}$ of DMEM medium were used as a control. They were incubated at $37^{\circ} \mathrm{C}$ and $5 \% \mathrm{CO}_{2}$ for $2 \mathrm{~h}$, after which the cells were washed with PBS twice and used for RNA extraction. All experiments were performed in triplicate.

Total RNA was isolated as per our previous report with slight modifications (Huang et al., 2016). Trizol Reagent (TransGen Biotech, Beijing, China) was used according to the manufacturer's instructions, and the concentration of RNA was determined using a spectrophotometer (Thermo Scientific, NanoDrop 1000, Wilmington, DE). Complementary DNA was synthesized using a PrimeScript RT reagent Kit with gDNA Eraser (TaKaRa, Dalian, China).

Real-time PCR was performed in an ABI 7900HT fast real-time PCR system (Applied Biosystems, Waltham, MA) as described before (Zhang et al., 2015). Each reaction was in a final volume of $20 \mu \mathrm{L}$ containing 10 $\mu \mathrm{L}$ of SYBR Primer EX TaqII (TaKaRa), $0.8 \mu \mathrm{L}(0.2$ $\mu M)$ of each of the primers, $0.4 \mu \mathrm{L}$ of ROX Reference Dye $(50 \times$; TaKaRa), $2 \mu \mathrm{L}$ of cDNA template, and 6 $\mu \mathrm{L}$ of milli-Q $\mathrm{H}_{2} \mathrm{O}$ (Millipore, Shanghai, China). The real-time PCR reaction began with 1 cycle of initial denaturation at $95^{\circ} \mathrm{C}$ for $30 \mathrm{~s}$, followed by 40 cycles of denaturation at $95^{\circ} \mathrm{C}$ for $5 \mathrm{~s}$, and primer annealing at $60^{\circ} \mathrm{C}$ for $1 \mathrm{~min}$. The gene relative expression level of BCL2-associated X protein (bax), tumor necrosis factor $\alpha(T N F-\alpha)$, interleukin $10(I L-10)$, heme oxygenase 1 (HO-1), cAMP response element binding protein $(C R E B)$, and protein kinase Akt $(A k t)$ were calculated by the $2^{-\Delta \Delta \mathrm{Ct}}$ method (Feng et al., 2010). The $\beta$-actin gene was used as internal control; PCR primers (Table 1) were designed using Oligo 7.0 software (Molecular Biology Insights Inc., Colorado Springs, CO).

\section{Statistical Analysis}

Statistical analysis was performed using the SPSS 13.0 software (SPSS Inc., Chicago, IL). Data were expressed as means \pm standard deviation and subjected 


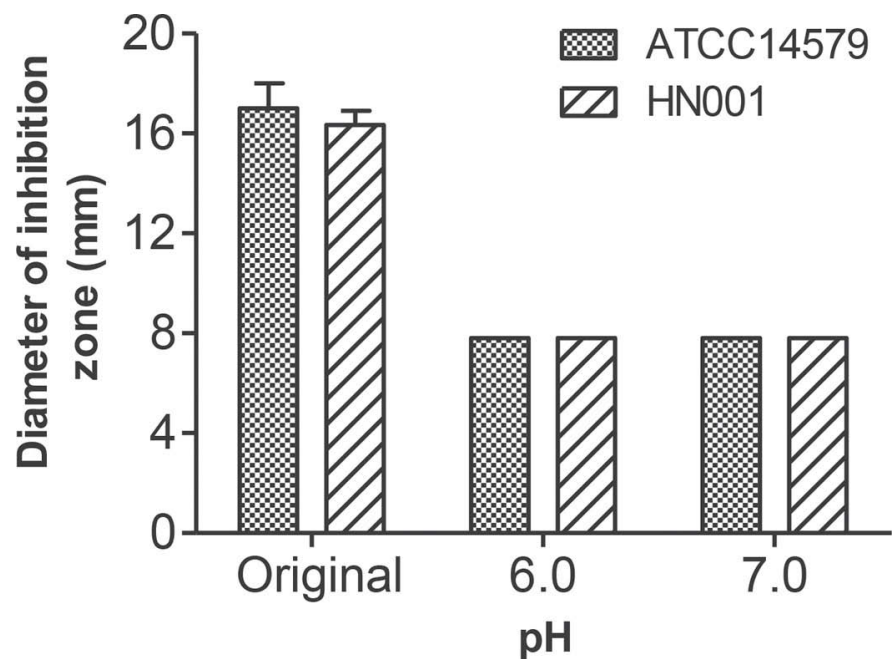

Figure 1. Antibacterial activity of Lactobacillus plantarum ZDY2013 suspension (original $\mathrm{pH}$ or adjusted to $\mathrm{pH} 6.0$ and 7.0) against enterotoxin-producing Bacillus cereus ATCC14579 and pathogenic B. cereus HN001. Bars show means \pm standard deviation.

to one-way or 2-way ANOVA. The $P$-values less than 0.05 were considered statistically significant.

\section{RESULTS}

\section{Antibacterial Activity}

The antibacterial activity of L. plantarum ZDY2013 supernatants was tested by adjusting the original $\mathrm{pH}$ (3.5) to 6.0 or 7.0. As shown in Figure 1, the supernatants of $L$. plantarum showed no antibacterial activity at $\mathrm{pH} 6.0$ and 7.0; however, the original supernatants were found to be most effective against enterotoxinproducing B. cereus ATCC14579 and pathogenic B. cereus HN001, with inhibition zones of $17.0 \pm 1.0$ and $16.3 \pm 0.58 \mathrm{~mm}$, respectively.

\section{Inhibition of B. cereus by L. plantarum in Milk Fermentation}

To determine whether growth of $B$. cereus might also be inhibited by $L$. plantarum during the food fermentation process, a co-incubation protocol was performed in sterile milk. As shown in Figure 2, a sharp decrease of the $\mathrm{pH}$ from $6.42 \pm 0.007$ to $4.8 \pm 0.035$ or $6.43 \pm$ 0.007 to $4.75 \pm 0.57$ was observed at the end of $48 \mathrm{~h}$ when L. plantarum ZDY2013 was co-incubated with B. cereus ATCC14579 or B. cereus HN001 (A/Z/milk or $\mathrm{H} / \mathrm{Z} /$ milk, Figure 2), respectively. However, the $\mathrm{pH}$ maintained above 6.08 when B. cereus (ATCC14579/ HN001) was cultured alone in milk (A/milk or $\mathrm{H} /$ milk, Figure 2), indicating that L. plantarum exhibited rapid acid production ability in milk.

Changing of $\mathrm{pH}$ might have affected the biomass of $B$. cereus and $L$. plantarum during the fermentation. As shown in Figure 3A, the counts of B. cereus co-incubated with $L$. plantarum $(\mathrm{A} / \mathrm{Z} /$ milk or $\mathrm{H} / \mathrm{Z} / \mathrm{milk}$, Figure 3 ) gradually increased 3 or 4 orders of magnitude at $36 \mathrm{~h}$ and then decreased 1 order of magnitude at $48 \mathrm{~h}$ of fermentation. However, for B. cereus grown in milk alone (A/milk or Z/milk, Figure 3$)$, its counts increased gradually and significant differences $(P<0.001)$ were found at 36 and $48 \mathrm{~h}$. These results explained how $L$. plantarum can inhibit the growth of $B$. cereus during milk fermentation, as the counts of $L$. plantarum in milk increased from initial $10^{5}$ to $10^{8} \mathrm{cfu} / \mathrm{mL}$ after $24 \mathrm{~h}$, and thus contributed to the continuous reduction in the $\mathrm{pH}$ value and reduction of the cell counts of $B$. cereus as mentioned.

\section{Effect of L. plantarum on B. cereus Adhesion to Intestinal Cells}

After the inhibition of $B$. cereus in vitro and during milk fermentation, the adhesion of $B$. cereus on Caco-2

Table 1. Primers used in this study

\begin{tabular}{|c|c|c|}
\hline Target & Primer sequence $\left(5^{\prime}-3^{\prime}\right)$ & Amplicon length (bp) \\
\hline$\overline{b a x}$ & $\begin{array}{l}\text { Forward (F): TGGGCTGGACATTGGACTTC } \\
\text { Reverse (R): GGGGTGAGGAGGCTTGAGG }\end{array}$ & 92 \\
\hline$T N F-\alpha$ & $\begin{array}{l}\text { F: TTTGATCCCTGACATCTGGA } \\
\text { R: GGCCTAAGGTCCACTTGTGT }\end{array}$ & 111 \\
\hline$I L-10$ & $\begin{array}{l}\text { F: AGGGAGGATGAGTGATTTGC } \\
\text { R: AACTGGGAGGAACACTGACC }\end{array}$ & 90 \\
\hline$H O-1$ & $\begin{array}{l}\text { F: CAGGCAGAGGGTGATAGAA } \\
\text { R: CTCTGGTCCTTGGTGTCA }\end{array}$ & 102 \\
\hline$C R E B$ & $\begin{array}{l}\text { F: ATGGAATCTGGAGCCGAG } \\
\text { R: CTGGGCTAATGTGGCAATC }\end{array}$ & 108 \\
\hline Akt & $\begin{array}{l}\text { F: GTAACCCCAACACGGATAGCG } \\
\text { R: TCTCCAGGGCGGGGTAGT }\end{array}$ & 87 \\
\hline$\beta$-actin & $\begin{array}{l}\text { F: GGGAACTGCCTGACTACCTC } \\
\text { R: CTTTGATGTCACGCACGATT }\end{array}$ & 93 \\
\hline
\end{tabular}


cells with the presence of $L$. plantarum was performed by inhibition, competition, and displacement assays. As shown in Figure 4A, L. plantarum was able to significantly inhibit, compete, and displace $B$. cereus compared with the control $(P<0.001)$. The adhesion ratio of $B$. cereus ATCC14579 was reduced to 19.12, 16.38 , and $18.00 \%$ of the control group, and the adhesion ratio of $B$. cereus HN001 was reduced to 25.86, 19.83 , and $39.28 \%$ of the control group. The 2 kinds of $B$. cereus were inhibited by $L$. plantarum with a similar trend, and the ideal inhibition strategy was competition. Additionally, a certain relationship was noted between inhibiting the adhesion of $B$. cereus and the concentration of L. plantarum. As shown in Figure 4B, the concentrations of $L$. plantarum in competition were higher than those in inhibition or displacement assays, all counts presented a significant increase than that in control $(P<0.01)$.

\section{The Caco-2 Cell Membrane Integrity}

Though L. plantarum can inhibit the adhesion of enterotoxin-producing $B$. cereus and pathogenic $B$. cereus on Caco-2 cells, the cytotoxicity of $B$. cereus supernatants on Caco-2 cells is still unknown. Cells treated by $B$. cereus supernatants damages the cell membrane integrity to produce $\mathrm{LDH}$, which is an indicator for

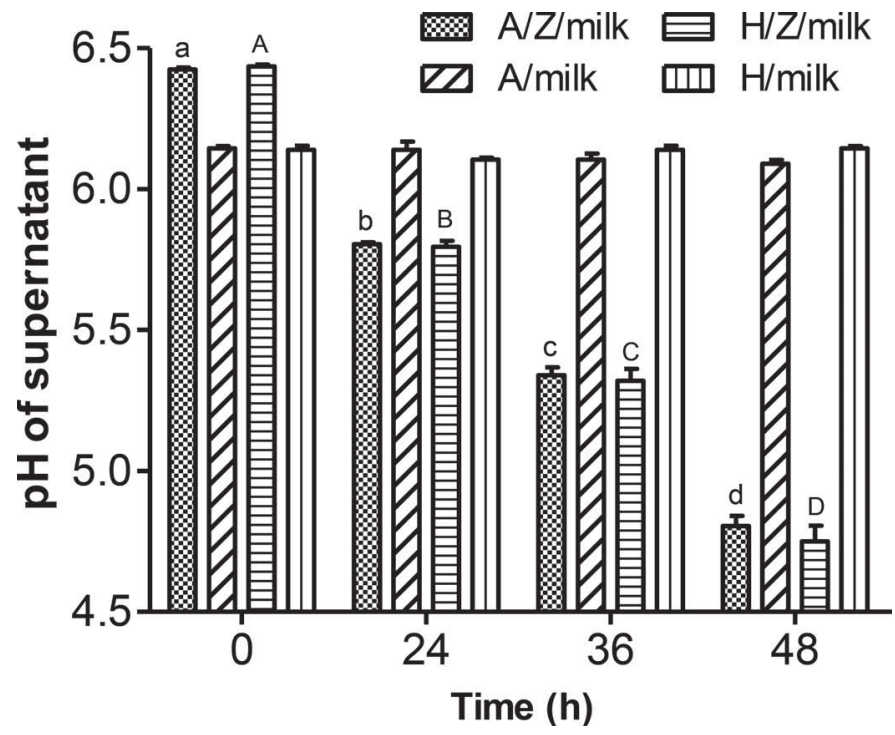

Figure 2. The development of $\mathrm{pH}$ during milk fermentation with Lactobacillus plantarum ZDY2013 in conjunction with Bacillus cereus ATCC14579 (A/Z/milk) or B. cereus HN001 (H/Z/milk). The control groups were milk fermentation with only $B$. cereus ATCC14579 (A) milk) or B. cereus $\mathrm{HN} 001(\mathrm{H} / \mathrm{milk})$ in $10 \%$ reconstituted sterile milk. The lowercase letters indicate statistically significant differences $(P<$ 0.001 ) in $\mathrm{pH}$ of $\mathrm{A} / \mathrm{Z} /$ milk over time, and the uppercase letters indicate statistically significant differences $(P<0.001)$ in $\mathrm{pH}$ of $\mathrm{H} / \mathrm{Z} /$ milk over time. Bars show means \pm standard deviation.
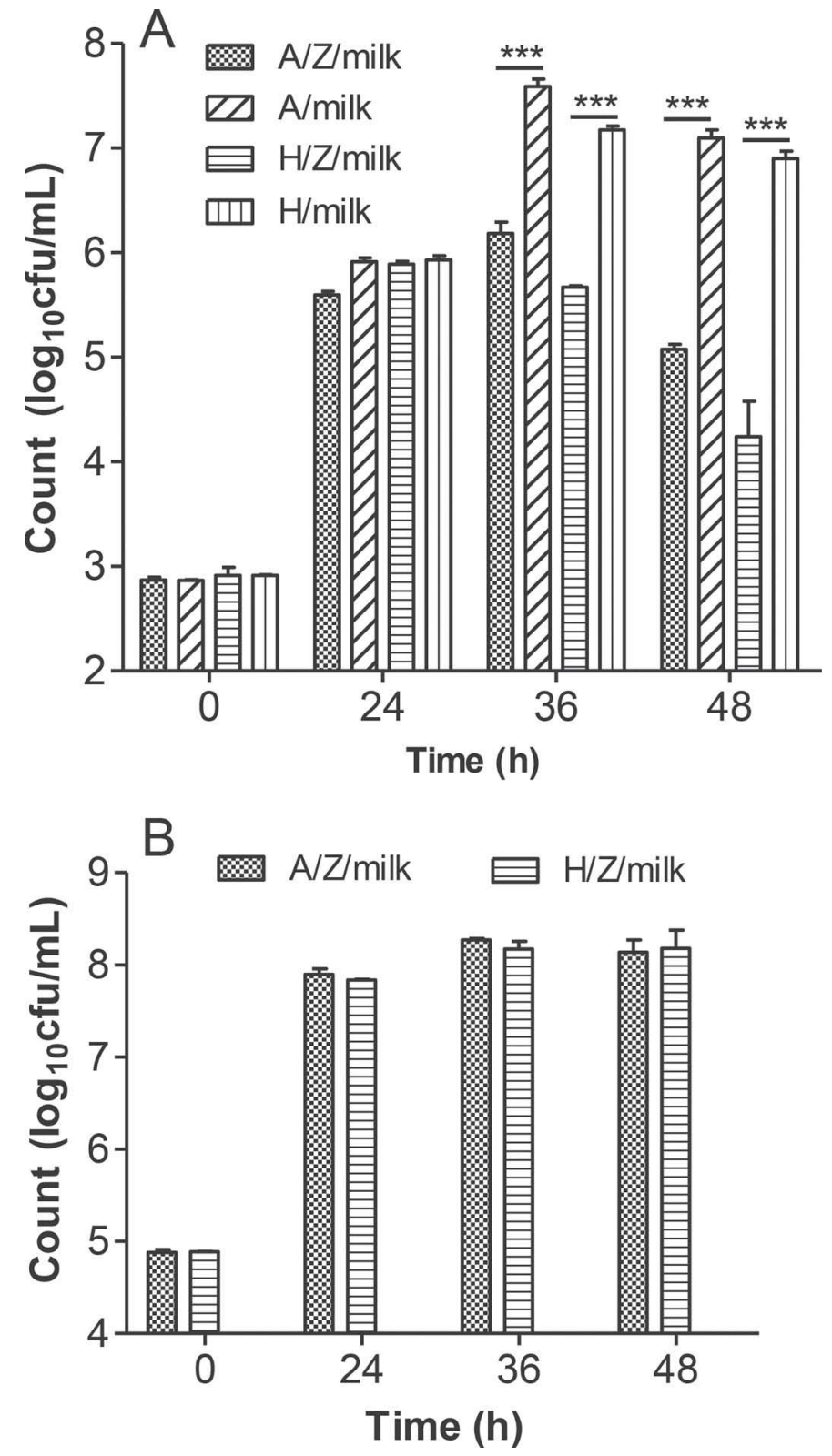

Figure 3. Growth of Bacillus cereus (ATCC14579/HN001) either alone or in conjunction with Lactobacillus plantarum (A) and L. plantarum co-incubated with B. cereus (ATCC14579/HN001) (B) in 10\% reconstituted sterile milk at $37^{\circ} \mathrm{C}$ for $48 \mathrm{~h}$. $* * * P<0.001 . \mathrm{A} / \mathrm{Z} / \mathrm{milk}=$ milk fermented with L. plantarum ZDY2013 and B. cereus ATCC14579; $\mathrm{A} /$ milk $=$ milk fermented with only $B$. cereus ATCC14579; H/Z/milk = milk fermented with Lactobacillus plantarum ZDY2013 and B. cereus $\mathrm{HN} 001 ; \mathrm{H} / \mathrm{milk}=$ milk fermented with only $B$. cereus HN001. Bars show means \pm standard deviation.

the cytotoxicity. As shown in Figure 5, the LDH activity decreased as the density of the supernatants of enterotoxin-producing B. cereus ATCC14579 or pathogenic B. cereus HN001 decreased (B. cereus, Figure 5). Furthermore, we tested the role of $10^{8} \mathrm{cfu}$ of $L$. plantarum (suspended in $1.6 \mathrm{~mL}$ of DMEM medium without antibiotics) when added to Caco-2 cells simultaneously 

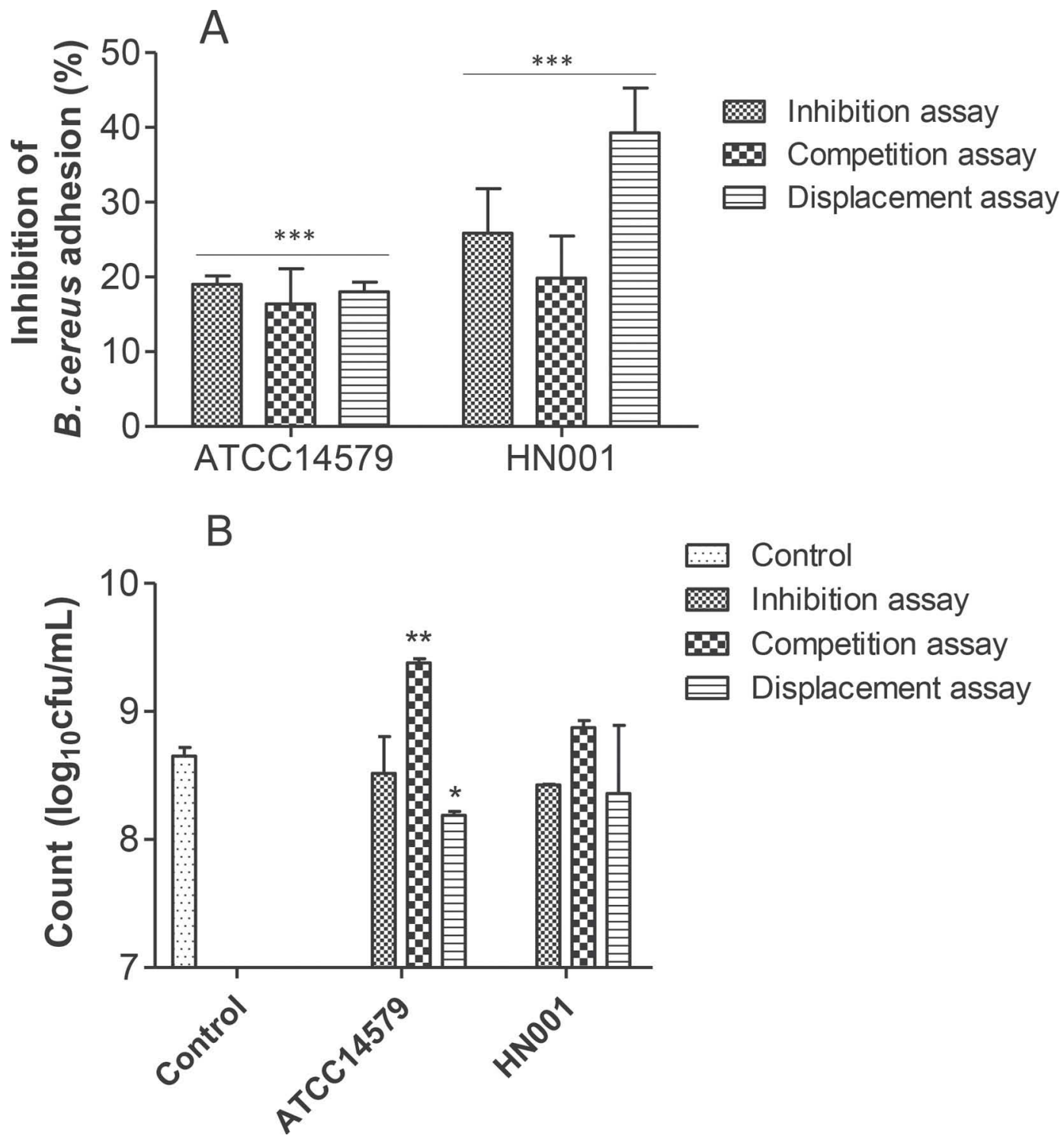

Figure 4. Antiadhesion assays (inhibition, competition, and displacement) of Bacillus cereus (ATCC14579/HN001) in the presence of Lactobacillus plantarum (A), and the concentration of L. plantarum after the antiadhesion assays (B). All the data were compared with nontreated group (control). ${ }^{*} P<0.05,{ }^{* *} P<0.01,{ }^{* * *} P<0.001$. Bars show means \pm standard deviation.

with $0.4 \mathrm{~mL}$ of supernatants of B. cereus (B. cereus/ ZDY2013, Figure 5). Whereas the results showed that the LDH activity was higher than that of the absence of $L$. plantarum, those of the 20 and $1.25 \%$ B. cereus ATCC14579 supernatants were significantly increased. Similar results have been found when treated with 2.5 and $1.25 \%$ B. cereus HN001 supernatants.

\section{Gene Expression Levels of Caco-2 Cells Induced by B. cereus Supernatants}

To further determine the antagonistic effect of $L$. plantarum on the cytotoxicity induced by B. cereus su- pernatants, we analyzed the expression levels of genes, such as bax (apoptosis), TNF- $\alpha$ (proinflammatory cytokine), IL-10 (anti-inflammatory cytokine), HO-1 (oxidative stress), CREB (proliferation), and Akt (proliferation), when Caco-2 cells treated with supernatants of pathogenic B. cereus HN001 alone or in conjunction with L. plantarum (Figure 6). The B. cereus HN001 supernatants induced a significant upregulation in the mRNA levels of bax, TNF- $\alpha, H O-1$, and $A k t(P<0.01)$ and caused a significant downregulation in the level of $I L-10(P<0.01)$ as compared with the control. However, except for $T N F-\alpha$, the levels of these mRNA had no significant difference than the control, and only $I L-10$ 


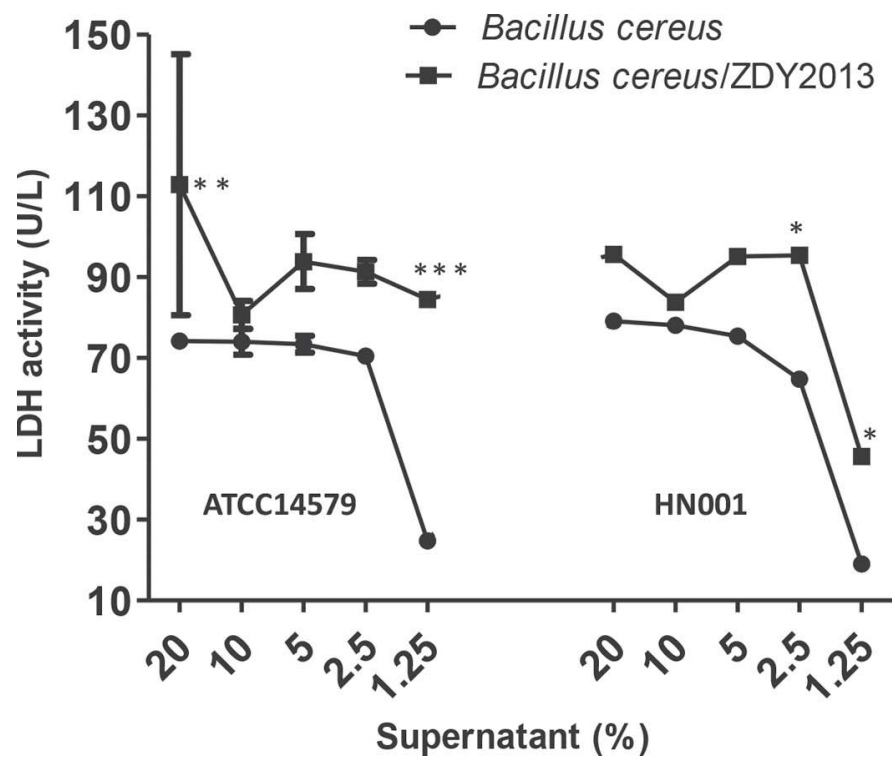

Figure 5. Extracellular lactate dehydrogenase (LDH) activity of Caco-2 cells after co-cultivation with Bacillus cereus HN001 supernatants (dilutions $1: 5$ to $1: 80$ ) in the absence (B. cereus) and presence (B. cereus/ZDY2013) of Lactobacillus plantarum. Statistical analysis was performed between B. cereus and B. cereus/ZDY2013 at the same supernatant; ${ }^{*} P<0.05,{ }^{* *} P<0.01,{ }^{* * *} P<0.001$. Data are shown as means \pm standard deviation.

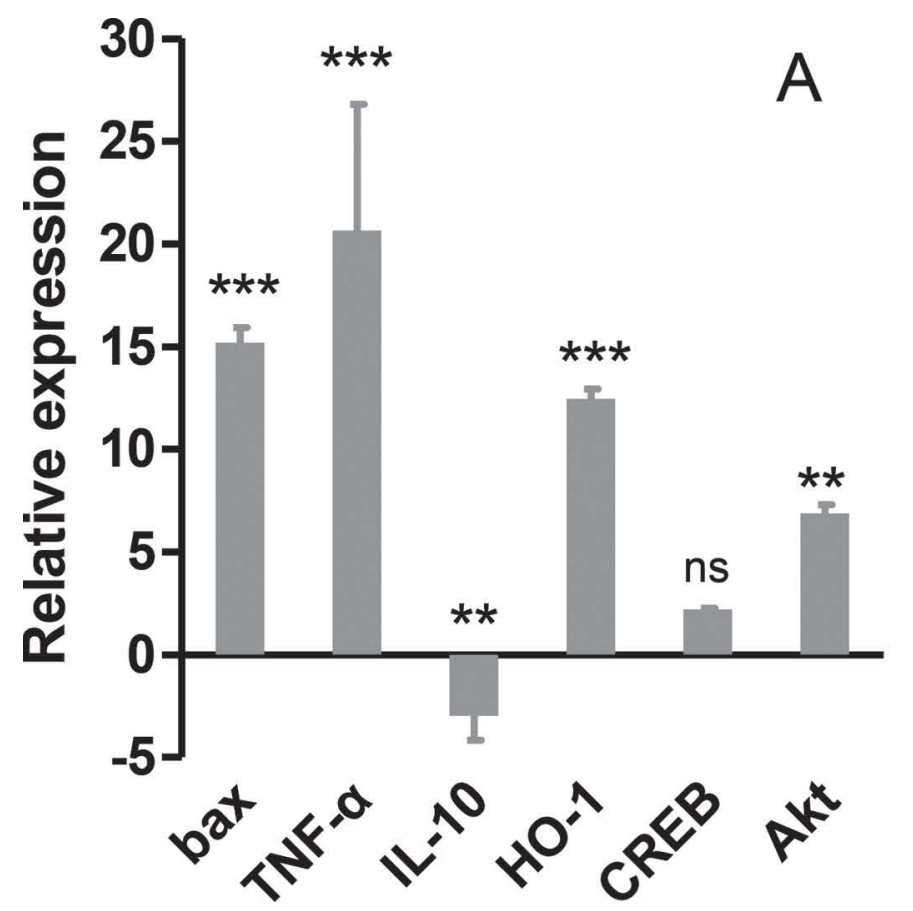

was downregulated when $L$. plantarum was used. These results confirmed an increased mRNA expression levels caused by $B$. cereus supernatants that was inhibited after co-incubated with L. plantarum.

\section{DISCUSSION}

Since the first occurrence of $B$. cereus in milk in 1916, this organism has become a common contaminant of raw milk and some dairy products (Ahmed et al., 1983; Rukure and Bester, 2001). To our knowledge, $B$. cereus can be inhibited by some probiotics. In our study, enterotoxin-producing B. cereus ATCC14579 and pathogenic B. cereus HN001 were inhibited by the original supernatants of L. plantarum ZDY2013, and the antibacterial effect disappeared when the $\mathrm{pH}$ of original supernatants was adjusted to 6.0 and 7.0. The results are consistent with previous reports that organic acids are major factors for inhibition of the growth of $B$. cereus and the main inhibitory compounds may be lactic acid (Yang et al., 2008; Crowley et al., 2013).

Lactic acid production has also been confirmed during milk fermentation, and $\mathrm{pH}$ decreased continuously when $B$. cereus was co-incubated with $L$. plantarum ZDY2013; likewise, the concentration of B. cereus began to decrease when the $\mathrm{pH}$ was reduced to about 5.0. This was in agreement with the findings that $\mathrm{pH}$

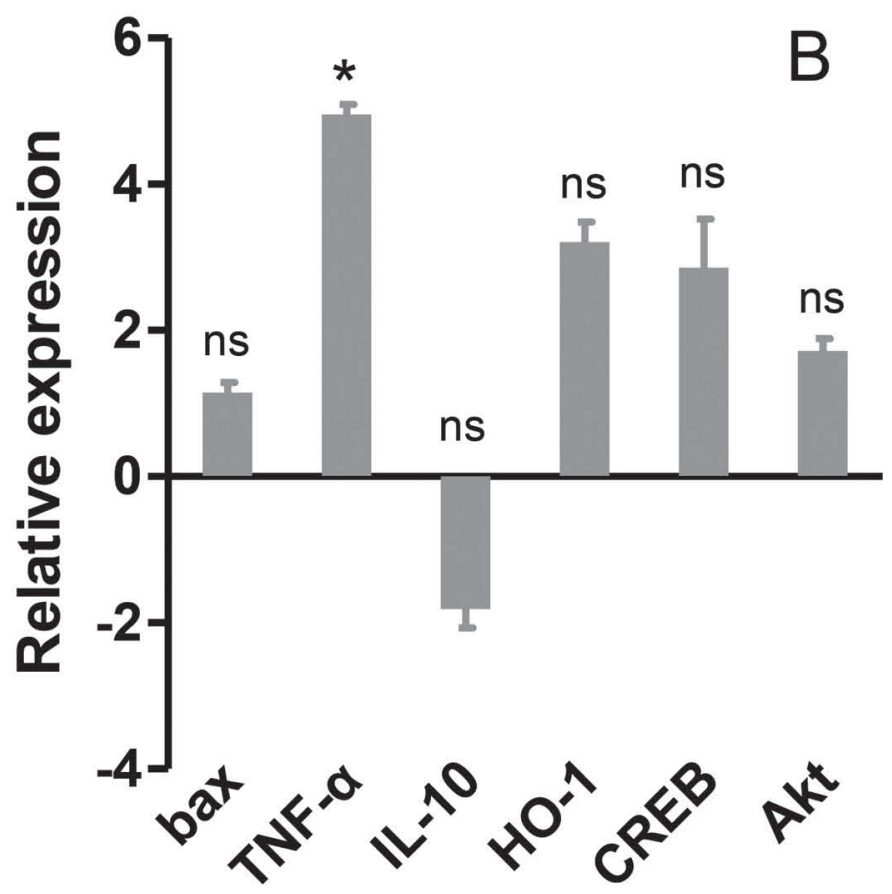

Figure 6. Effect of Bacillus cereus HN001 supernatants alone (A) or in conjunction with Lactobacillus plantarum (B) on the mRNA expression of bax (apoptosis), TNF- $\alpha$ (pro-inflammatory cytokine), IL-10 (anti-inflammatory cytokine), HO-1 (oxidative stress), CREB (proliferation), and $A k t$ (proliferation). ${ }^{*} P<0.05,{ }^{* *} P<0.01,{ }^{* * *} P<0.001$. Bars show means \pm standard deviation. 
4.9 to 5.0 is a critical value for inhibiting the growth of $B$. cereus (Røssland et al., 2005). In addition, the concentration of $L$. plantarum could reach up to $10^{8}$ $\mathrm{cfu} / \mathrm{mL}$ after $24 \mathrm{~h}$ of fermentation $(\mathrm{pH}$ is about 5.5) and remain for a long time, which was consistent with previous studies (Rukure and Bester, 2001). Thus, pH is considered as a critical control parameter for safe production of fermented dairy products (Adams and Nicolaides, 1997).

Considering that $B$. cereus can adhere to eukaryotic cells and may pose a threat to human health when presented in high numbers (Ramarao and Lereclus, 2006; Stenfors Arnesen et al., 2008), we used inhibition, competition, and displacement assays to estimate the ability of L. plantarum ZDY2013 to prevent the adhesion of enterotoxin-producing B. cereus ATCC14579 and pathogenic B. cereus HN001 to intestinal epithelial cells. Our results showed that all of the adhesion of the 2 strains of $B$. cereus on Caco- 2 cells could be inhibited by $L$. plantarum, and all the adhesions have been reduced to below $40 \%$ as compared with that of the control. Both B. cereus ATCC14579 and B. cereus HN001 showed the highest values of inhibition by L. plantarum in the competition assays, and the lowest values of displacement. It was hypothesized that $L$. plantarum might compete with the common adhesion receptors with pathogens in competition assays (García-Ruiz et al., 2014) and produce antimicrobial compounds or antiadhesion factors to inhibit $B$. cereus in the displacement profiles (Abedi et al., 2013). However, only a few reports focus on the antagonistic mechanism of probiotics against pathogens on antimicrobial compounds (e.g., lactic acid, hydrogen peroxide, and bacteriocin; Ššković et al., 2010), adhesive factors (e.g., GAPDH), and elongation factor-Tu (Siciliano and Mazzeo, 2012).

Binding of $B$. cereus to intestinal epithelial cells triggers cytotoxicity related to their bacterial toxins (Minnaard et al., 2004). In the current study, we have shown a positive correlation between LDH activity and toxic doses of $B$. cereus supernatants, which was similar to the finding that LDH release of Caco- 2 cells by $B$. cereus B10502 supernatant infection (Ruas-Madiedo et al., 2010). In particular, treatment with L. plantarum did not show protection capability to prevent the $\mathrm{LDH}$ release, but an increase of LDH activity was observed, indicating that it may be due to the effect of organic acid or LDH production by L. plantarum itself (Dennis and Kaplan, 1960). Regarding the antagonism of L. plantarum against the mRNA expression of bax, $T N F-\alpha, I L-10, H O-1, C R E B$, and Akt induced by $B$. cereus HN001 supernatants, our results showed that L. plantarum was able to diminish the fold change of relative expression, which indicated the bacteria can in- hibit apoptosis, proinflammatory cytokine production, and oxidative stress levels.

In conclusion, the L. plantarum ZDY2013 isolated from a fermented acid bean is able to exert an antagonistic effect on the growth of enterotoxin-producing $B$. cereus ATCC14579 and pathogenic B. cereus HN001 in vitro and during milk fermentation. The strain also affects antiadhesion on Caco-2 cells and blocks the level of gene expression induced by $B$. cereus HN001 supernatants. Although the antagonistic mechanisms against pathogens are still not fully understood, probiotics could act by producing adhesive factors or by blocking relevant receptors on eukaryotic cell surface. However, these need further experimental data for confirmation.

\section{ACKNOWLEDGMENTS}

This work was supported by National Natural Science Foundation of China (31360377 and 31260363; Beijing, China), Ganpo Talent 555 Engineering Project of Jiangxi Province (2013; Jiangxi, China), and Graduate student innovation special funds of Jiangxi Province (YC2015-B013; Jiangxi, China).

\section{REFERENCES}

Abedi, D., S. Feizizadeh, V. Akbari, and A. Jafarian-Dehkordi. 2013. In vitro anti-bacterial and anti-adherence effects of Lactobacillus delbrueckii subsp bulgaricus on Escherichia coli. Res. Pharm. Sci. 8:260-268.

Adams, M. R., and L. Nicolaides. 1997. Review of the sensitivity of different foodborne pathogens to fermentation. Food Contr. 8:227239.

Ahmed, A. A., M. K. Moustafa, and E. H. Marth. 1983. Incidence of Bacillus cereus in milk and some milk products. J. Food Prot. 46:126-128.

Bravo-Ferrada, B. M., S. Gonçalves, L. Semorile, N. Santos, E. Tymczyszyn, and A. Hollmann. 2015. Study of surface damage on cell envelope assessed by AFM and flow cytometry of Lactobacillus plantarum exposed to ethanol and dehydration. J. Appl. Microbiol. 118:1409-1417.

Chouraqui, J.-P., L.-D. Van Egroo, and M.-C. Fichot. 2004. Acidified milk formula supplemented with Bifidobacterium lactis: Impact on infant diarrhea in residential care settings. J. Pediatr. Gastroenterol. Nutr. 38:288-292.

Collado, M. C., J. Meriluoto, and S. Salminen. 2007. Role of commercial probiotic strains against human pathogen adhesion to intestinal mucus. Lett. Appl. Microbiol. 45:454-460.

Collado, M. C., L. Jalonen, J. Meriluoto, and S. Salminen. 2006. Protection mechanism of probiotic combination against human pathogens: in vitro adhesion to human intestinal mucus. Asia Pac. J. Clin. Nutr. 15:570-575.

Crowley, S., J. Mahony, and D. van Sinderen. 2013. Broad-spectrum antifungal-producing lactic acid bacteria and their application in fruit models. Folia Microbiol. (Praha) 58:291-299.

da Silva Sabo, S., M. Vitolo, J. M. D. González, and R. P. de Souza Oliveira. 2014. Overview of Lactobacillus plantarum as a promising bacteriocin producer among lactic acid bacteria. Food Res. Int. 64:527-536.

Dennis, D., and N. O. Kaplan. 1960. D-and L-lactic acid dehydrogenases in Lactobacillus plantarum. J. Biol. Chem. 235:810-818. 
Derrien, M., and J. E. van Hylckama Vlieg. 2015. Fate, activity, and impact of ingested bacteria within the human gut microbiota. Trends Microbiol. 23:354-366.

Feng, Y., J. Gong, H. Yu, Y. Jin, J. Zhu, and Y. Han. 2010. Identification of changes in the composition of ileal bacterial microbiota of broiler chickens infected with Clostridium perfringens. Vet. Microbiol. 140:116-121.

García-Ruiz, A., D. G. de Llano, A. Esteban-Fernández, T. Requena, B. Bartolomé, and M. V. Moreno-Arribas. 2014. Assessment of probiotic properties in lactic acid bacteria isolated from wine. Food Microbiol. 44:220-225.

Górska, S., M. Schwarzer, W. Jachymek, D. Srutkova, E. Brzozowska, H. Kozakova, and A. Gamian. 2014. Distinct immunomodulation of bone marrow-derived dendritic cell responses to Lactobacillus plantarum WCFS1 by two different polysaccharides Isolated from Lactobacillus rhamnosus LOCK 0900. Appl. Environ. Microbiol. 80:6506-6516.

Huang, R., M. Pan, C. Wan, N. P. Shah, X. Tao, and H. Wei. 2016. Physiological and transcriptional response as well as cross protection of Lactobacillus plantarum ZDY2013 under acid stress. J. Dairy Sci. http://dx.doi.org/10.3168/jds.2015-9993.

Huang, R., X. Tao, C. Wan, S. Li, H. Xu, F. Xu, N. P. Shah, and H Wei. 2015. In vitro probiotic characteristics of Lactobacillus plantarum ZDY 2013 and its modulatory effect on gut microbiota of mice. J. Dairy Sci. 98:5850-5861.

Hwang, J. Y., and J. Park. 2015. Characteristics of enterotoxin distribution, hemolysis, lecithinase, and starch hydrolysis of Bacillus cereus isolated from infant formulas and ready-to-eat foods. J. Dairy Sci. 98:1652-1660.

Kuda, T., M. Nemoto, M. Kawahara, S. Oshio, H. Takahashi, and B. Kimura. 2015. Induction of the superoxide anion radical scavenging capacity of dried 'funori' Gloiopeltis furcata by Lactobacillus plantarum S-SU1 fermentation. Food Funct. 6:2535-2541.

Leahy, S. C., D. Higgins, G. Fitzgerald, and D. v. Sinderen. 2005. Getting better with bifidobacteria. J. Appl. Microbiol. 98:1303-1315.

Leite, A. M., M. Miguel, R. Peixoto, P. Ruas-Madiedo, V. Paschoalin B. Mayo, and S. Delgado. 2015. Probiotic potential of selected lactic acid bacteria strains isolated from Brazilian kefir grains. J. Dairy Sci. 98:3622-3632.

Li, S., Y. Zhao, L. Zhang, X. Zhang, L. Huang, D. Li, C. Niu, Z. Yang, and Q. Wang. 2012. Antioxidant activity of Lactobacillus plantarum strains isolated from traditional Chinese fermented foods. Food Chem. 135:1914-1919.

Marco, M. L., and S. Tachon. 2013. Environmental factors influencing the efficacy of probiotic bacteria. Curr. Opin. Biotechnol. 24:207213

Minnaard, J., V. Lievin-Le Moal, M.-H. Coconnier, A. L. Servin, and P. F. Pérez. 2004. Disassembly of F-actin cytoskeleton after interaction of Bacillus cereus with fully differentiated human intestinal Caco-2 cells. Infect. Immun. 72:3106-3112.
Ngamwongsatit, P., W. Buasri, P. Pianariyanon, C. Pulsrikarn, M. Ohba, A. Assavanig, and W. Panbangred. 2008. Broad distribution of enterotoxin genes (hblCDA, nheABC, cytK, and entFM) among Bacillus thuringiensis and Bacillus cereus as shown by novel primers. Int. J. Food Microbiol. 121:352-356.

Ramarao, N., and D. Lereclus. 2006. Adhesion and cytotoxicity of $B a-$ cillus cereus and Bacillus thuringiensis to epithelial cells are FlhA and PlcR dependent, respectively. Microbes Infect. 8:1483-1491.

Røssland, E., T. Langsrud, and T. Sørhaug. 2005. Influence of controlled lactic fermentation on growth and sporulation of Bacillus cereus in milk. Int. J. Food Microbiol. 103:69-77.

Ruas-Madiedo, P., M. Medrano, N. Salazar, D. Los Reyes-Gavilán, P. Pérez, and A. Abraham. 2010. Exopolysaccharides produced by Lactobacillus and Bifidobacterium strains abrogate in vitro the cytotoxic effect of bacterial toxins on eukaryotic cells. J. Appl. Microbiol. 109:2079-2086.

Rukure, G., and B. H. Bester. 2001. Survival and growth of Bacillus cereus during Gouda cheese manufacturing. Food Contr. 12:31-36.

Siciliano, R. A., and M. F. Mazzeo. 2012. Molecular mechanisms of probiotic action: a proteomic perspective. Curr. Opin. Microbiol. 15:390-396.

Stenfors Arnesen, L. P., A. Fagerlund, and P. E. Granum. 2008. From soil to gut: Bacillus cereus and its food poisoning toxins. FEMS Microbiol. Rev. 32:579-606.

Šušković, J., B. Kos, J. Beganović, A. Leboš Pavunc, K. Habjanič, and S. Matošić. 2010. Antimicrobial activity-the most important property of probiotic and starter lactic acid bacteria. Food Technol. Biotechnol. 48:296-307.

Yang, Y., W.-Y. Tao, Y.-J. Liu, and F. Zhu. 2008. Inhibition of Bacillus cereus by lactic acid bacteria starter cultures in rice fermentation. Food Contr. 19:159-161.

Zago, M., M. E. Fornasari, D. Carminati, P. Burns, V. Suàrez, G. Vinderola, J. Reinheimer, and G. Giraffa. 2011. Characterization and probiotic potential of Lactobacillus plantarum strains isolated from cheeses. Food Microbiol. 28:1033-1040.

Zhang, Y., and P. V. Vadlani. 2015. Lactic acid production from biomass-derived sugars via co-fermentation of Lactobacillus brevis and Lactobacillus plantarum. J. Biosci. Bioeng. 119:694-699.

Zhang, Z., L. Feng, H. Xu, C. Liu, N. P. Shah, and H. Wei. 2016 Detection of viable enterotoxin-producing Bacillus cereus and analysis of toxigenicity from ready-to-eat foods and infant formula milk powder by multiplex PCR. J. Dairy Sci. http://dx.doi org/10.3168/jds.2015-10147.

Zhang, Z., W. Liu, H. Xu, Z. P. Aguilar, N. P. Shah, and H. Wei. 2015. Propidium monoazide combined with real-time PCR for selective detection of viable Staphylococcus aureus in milk powder and meat products. J. Dairy Sci. 98:1625-1633. 